\title{
Flame transition velocities at various intercylinder spac- ing for side-by-side dual blowing cylindrical burners
}

\author{
Hsing-Sheng Chai ${ }^{1 *}$, Vong-Ren Chen ${ }^{2}$, Chiun-Hsun Chen ${ }^{3}$ \\ ${ }^{1}$ Department of Air Transport Industry, Aletheia University, Taipei, Taiwan \\ ${ }^{2,3}$ Department of Mechanical Engineering, National Chiao Tung University, Hsinchu, Taiwan
}

\section{Keywords \\ Counter flow flame \\ Porous cylindrical burner \\ Flame transition velocity}

Received: 17 April 2018

Accepted: 29 May 2018

Published: 12 June 2018

\begin{abstract}
This study investigates the flame transition velocities at various intercylinder separation distances for side-by-side dual blowing cylindrical burners. The flame transition velocity is defined as the airflow velocity at which the envelope flames over the two burners transform into two separate wake flames. The transition velocity increases as $\mathrm{L}$ decreases through the range of $1.2 \mathrm{D} \leqq L \leqq 2.5 \mathrm{D}$ ( $\mathrm{D}$ is diameter of cylindrical burner). When $L>2.5 \mathrm{D}$, the transition velocity remains constant because the two flames do not interact with each other.
\end{abstract}

(C) 2018 The Author(s). Published by TAF Publishing.

\section{INTRODUCTION}

This study investigates the flame transition velocities at various intercylinder separation distances for side-by-side dual blowing porous circular cylindrical burners (Tsuji burners). Methane is the type of fuel used, and it is ejected from the entire porous surface of the burner. This study is an extension of $[1,2]$, which experimentally investigated counterflow diffusion flame behaviors over a Tsuji burner. The primary goal of this investigation is to conduct an experiment to measure the flame transition velocity, which is an inflow velocity that causes an envelope flame to transform into a wake flame. Therefore, the flame transition velocity is a function of the intercylinder spacing $(L)$ between the dual Tsuji burners at a fixed fuel ejection rate. The experimental configuration is schematically depicted in Figure 1 , and it is identical to the set-up that was used by [3,4], except that an extra burner is mounted in the wind tunnel.

\footnotetext{
${ }^{*}$ Corresponding author: Hsing Sheng Chai

†email: au4289@mail.au.edu.tw
}

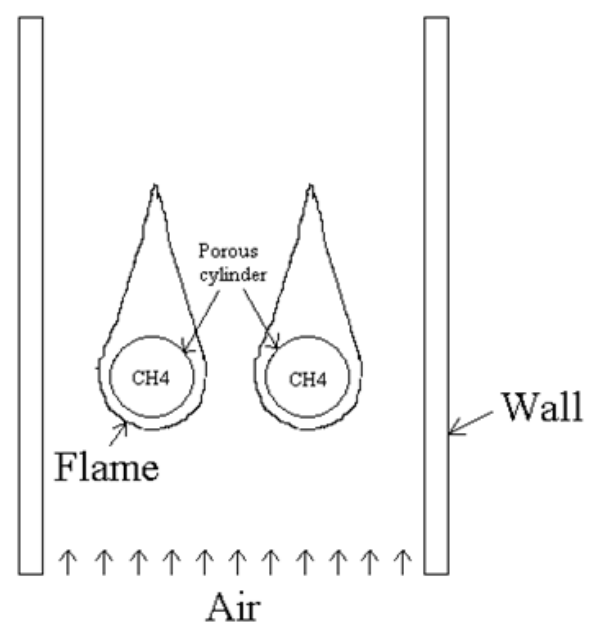

Fig. 1. Schematic configuration of the physical structure

The flame transition velocity over dual Tsuji burners was first examined in 1995 by [5] and [6], and they found that the flame transition velocity is a function of intercylinder spacing $(L)$. In 2005, a numerical study by [1] explored 
counter-diffusion flame behavior over twin Tsuji burners as a function of intercylinder spacing from 1.2D to 4D. At large separations, the dual flames burned separately, similar to two individual flames. At moderate spacing, the two counterflow diffusion flames connected in the wake region and exhibited an " $\cap$ " shape. When the intercylinder spacing is small, the two flames eventually merge and form a single diffusion flame. Additionally, the corresponding combustion efficiency is a strong function of the separation distance.

Numerous studies have theoretically and experimentally explored the Tsuji burner flame. [7] conducted an intensive review of the literature on the counterflow diffusion flame over a Tsuji burner. In their investigation, they employed the two-dimensional model to simulate this topic. [8] modified the original combustion model of [7] to apply a four- step chemical kinetics method rather than one-step overall kinetics. In this study, one more burner is added to the test section in a side-by-side arrangement. The goal is to measure the flame transition velocity over dual Tsuji burners. The intercylinder spacing $(L)$ is varied while the fuel ejection rate is fixed. In the experiment, the multiple side-byside flame structures are captured with digital video.

\section{EXPERIMENTAL APPARATUS}

The experimental setup in this investigation is an extension of the basic setup of [1]. The major difference is that an extra burner is introduced into the test section of the combustion tunnel. The apparatus consists of three major components: the wind tunnel, two Tsuji burners, and the measurement instruments, whose configuration is depicted in Figure 2.

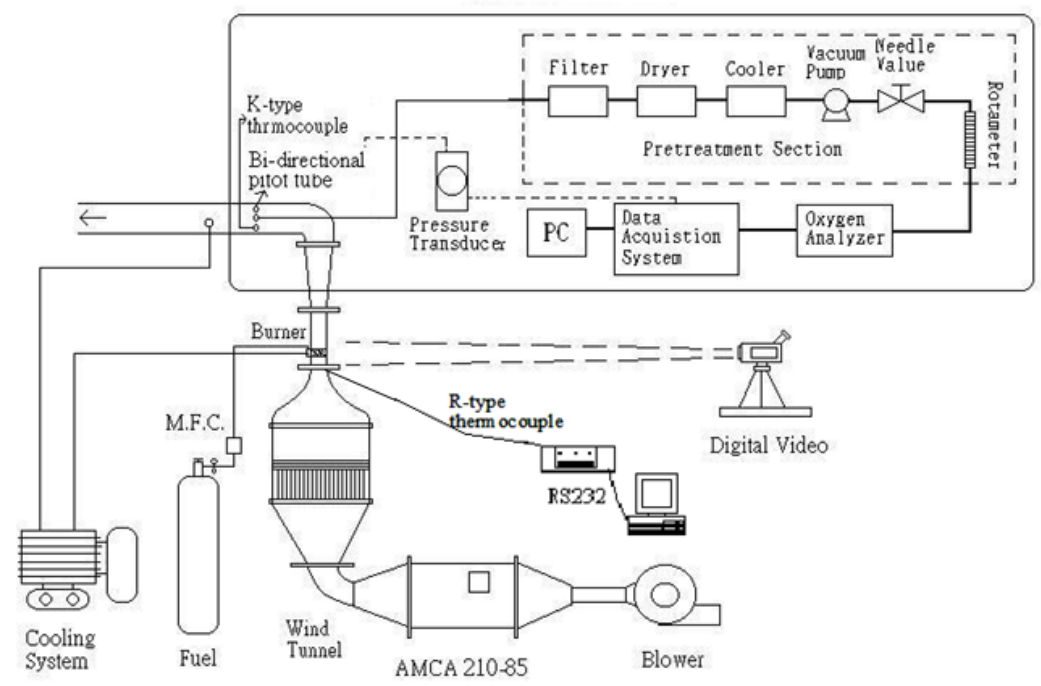

Fig. 2. Schematic drawing of the overall experimental system

\section{A. Wind Tunnel}

The wind tunnel is composed of five components: the blower, diffuser, flow straightener, contraction, and test section. Most of the design concepts for this type of wind tunnel are taken from a NIST (National Institute of Standards and Technology) study [9]. Furthermore, the design satisfies the AMCA 210-85 standard [10]. At the rim of the testsection entrance, seven holes can be used to install sensors that confirm the uniformity of flow (Figure 3). These sensors are hot wires. If the values measured by the hot wires are approximately uniform, then the flow is essentially uniform and stable ahead of the burners, as displayed in Figure 4.

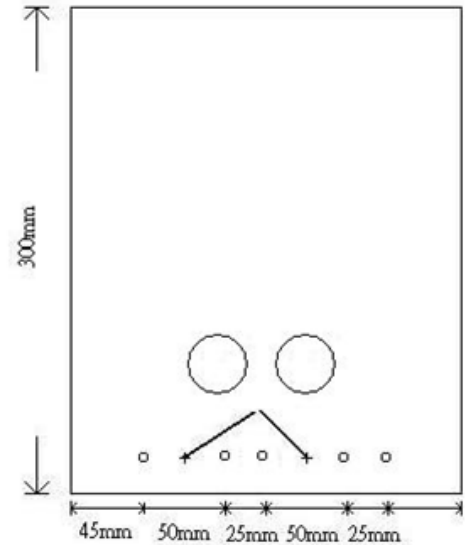

Fig. 3. Hot wire position 


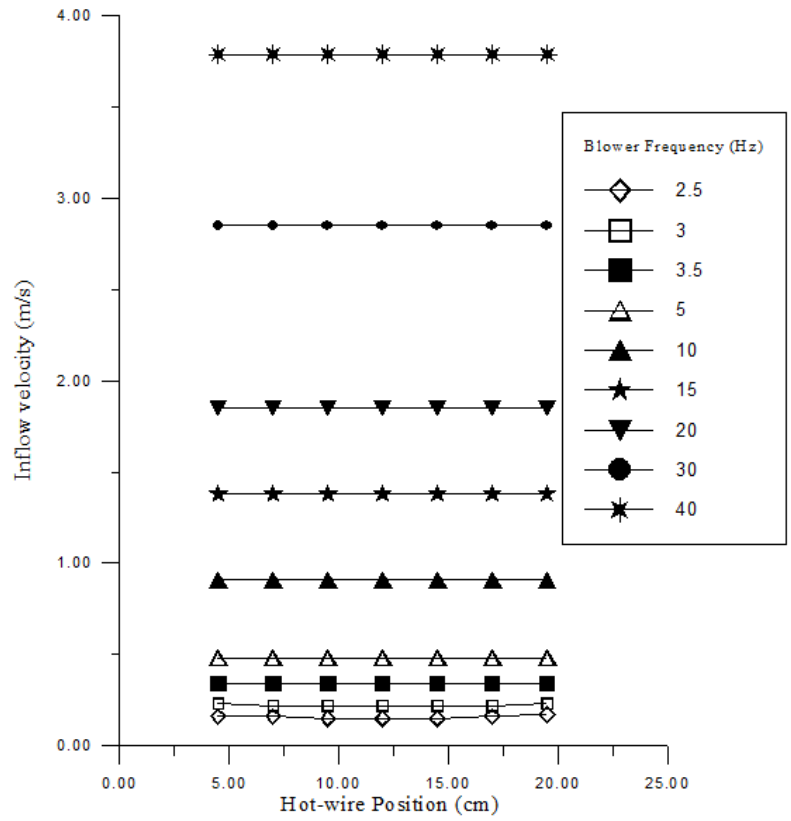

Fig. 4. Inflow velocity at each position in the test section

\section{B. Uncertainty Analysis}

Uncertainty analysis is conducted to evaluate the uncertainty in the experimental results. Formulae for evaluating the levels of uncertainty in the experimental results can be found in numerous reports $[11,12]$ and textbooks $[13,14,15]$. Accordingly, Table 1 summarizes the results of the uncertainty analysis.

TABLE 1

\begin{tabular}{|c|c|}
\hline Parameters & Uncertainty \\
\hline $\mathrm{D}_{i}, \mathrm{D}_{o}, \mathrm{~L}_{B}, \mathrm{a}, \mathrm{b}$ & $\pm 0.5 \mathrm{~mm}$ \\
\hline A & $\pm 1.267 \%$ \\
\hline $\mathrm{A}_{\text {Burner }}$ & $\pm .084 \%$ \\
\hline$v$ & $\pm 0.09 \%$ \\
\hline $\mathrm{T}$ & $\pm 0.5 \mathrm{C}$ \\
\hline$P$ & \pm 1 torr \\
\hline $\mathrm{Q}_{\text {fuel }}$ & $\pm 1 \%$ \\
\hline $\mathrm{U}_{i n}$ & $\pm 2.54 \%$ \\
\hline $\mathrm{V}_{\mathrm{w}}$ & $\pm 2.31 \%$ \\
\hline $\mathrm{Re}$ & $\pm 3.04 \%$ \\
\hline $\mathrm{RH}$ & $\pm 2.5 \%$ \\
\hline $\mathrm{T}_{t}$ & $\pm 0.2 \%$ \\
\hline
\end{tabular}

\section{Experimental Repeatability}

Table 2 presents the experimental repeatability of transition velocities at each separation distance. The error is defined as the ratio of the absolute difference between the maximum and minimum values among the three data to their average. The errors are clearly acceptable and are shown in Figure 5.

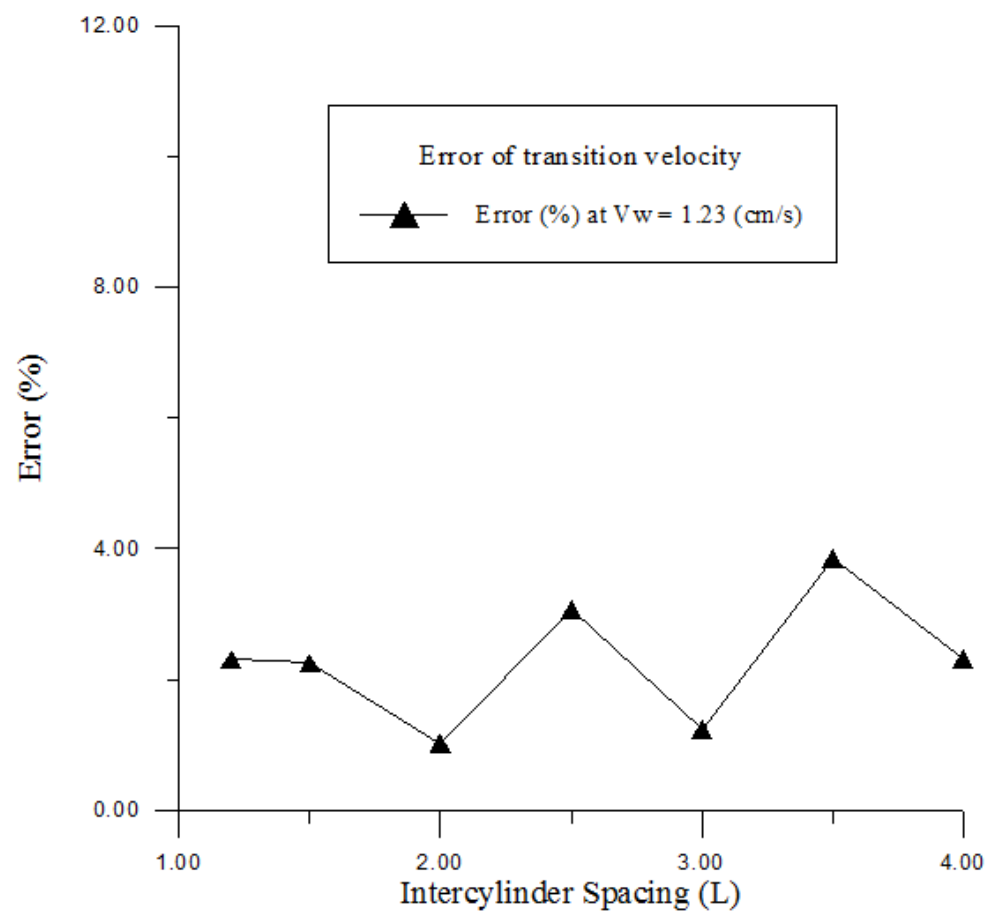

Fig. 5. Errors of experimental repeatability 
TABLE 2

EXPERIMENTAL REPEATABILITY

\begin{tabular}{llllll}
\hline \hline $\begin{array}{l}\text { Intercylinder } \\
\text { spacing (L) }\end{array}$ & $\begin{array}{l}\text { Transition } \\
\text { velocity } \\
\text { measured) } \\
(\mathrm{m} / \mathrm{s})\end{array}$ & $\begin{array}{l}\text { Transition } \\
\text { velocity } \\
\text { measured }) \\
(\mathrm{m} / \mathrm{s})\end{array}$ & $\begin{array}{l}\text { Transition } \\
\text { velocity } \\
\text { measured }) \\
(\mathrm{m} / \mathrm{s})\end{array}$ & $\begin{array}{l}\text { Average value } \\
\text { of three times } \\
(\%)\end{array}$ & Error (\%) \\
\hline 1.2D & 0.87 & 0.87 & 0.85 & 0.863 & 2.3 \\
1.5D & 0.71 & 0.7 & 0.716 & 0.709 & 2.25 \\
2D & 0.68 & 0.685 & 0.678 & 0.681 & 1.02 \\
2.5D & 0.65 & 0.64 & 0.66 & 0.65 & 3.07 \\
3D & 0.65 & 0.645 & 0.653 & 0.649 & 1.23 \\
3.5D & 0.65 & 0.66 & 0.635 & 0.648 & 3.85 \\
4D & 0.65 & 0.64 & 0.655 & 0.648 & 2.31 \\
\hline \hline
\end{tabular}

\section{RESULTS AND DISCUSSION}

\section{A. Flame Transition Velocities at Various Intercy linder Spacing}

This experiment measures the transition velocity as a function of intercylinder spacing $(L)$ under a fixed fuel ejection rate of $1.23 \mathrm{~cm} / \mathrm{s}$. The flame transition velocity is defined as the airflow velocity at which the envelope flames over the two burners transform into two separate wake flames. Figure 6 shows the results for this experiment. The transition velocity is $0.87 \mathrm{~m} / \mathrm{s}$ for $L=1.2 \mathrm{D}, 0.71 \mathrm{~m} / \mathrm{s}$ for $L=1.5 \mathrm{D}, 0.68$ $\mathrm{m} / \mathrm{s}$ for $L=2 \mathrm{D}$, and $0.65 \mathrm{~m} / \mathrm{s}$ for $L=2.5 \mathrm{D}$. Figure 6 demonstrates that when $L<2.5 \mathrm{D}$, the transition velocity increases as the gap between the two burners decreases. When $L \geqq$ $2.5 \mathrm{D}$, the transition velocity remains at a constant $0.65 \mathrm{~m} / \mathrm{s}$.

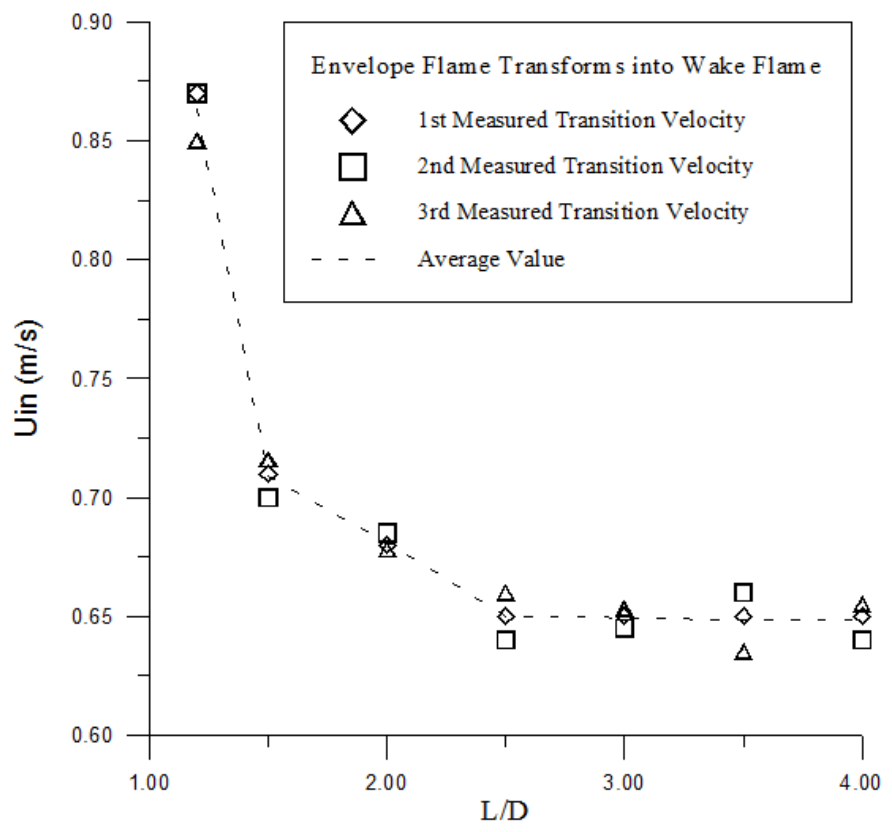

Fig. 6. Transition velocity as a function of intercylinder spacing $\left(\mathrm{V}_{\mathrm{w}}\right.$

$$
=1.23 \mathrm{~cm} / \mathrm{s} \text { ) }
$$

When the intercylinder spacing is $1.2 \mathrm{D}$, the transition velocity is $0.87 \mathrm{~m} / \mathrm{s}$, which is the highest in Figure 6. The two almost-combined burners behave as a sole bluff body and can substantially retard the incoming flow intensity by further incorporating the forward ejection fuel. Consequently, the flame can be sustained under high-velocity airflow. Figure 7 plots the flame variation process as a function of airflow velocity in this case. In Figure 7, both of the envelope flames that surround the two burners are quite similar. However, the flame stretching effect can still be observed. 
As the flow velocity increases from $0.48 \mathrm{~m} / \mathrm{s}$ to $0.83 \mathrm{~m} / \mathrm{s}$, the flame becomes thinner and the merge point moves slightly downstream. Notably, an extra blue zone exists just behind the merge point in Figure 7 that is not present in Figure 7. Clearly, the air can now penetrate the gap and mix with the fuel. Subsequently, the mixture is ignited by the heat upstream, initiating the reaction. Therefore, the local reaction zone expands, pushing the outer flames outward and the contraction further downstream.

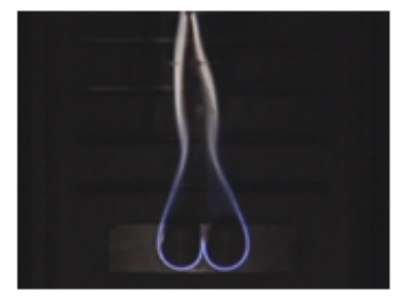

(a)

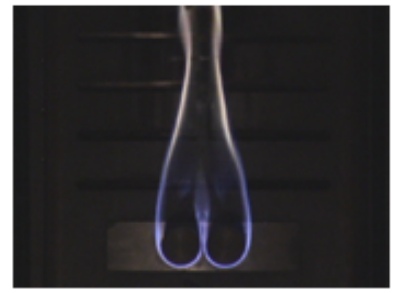

(b)

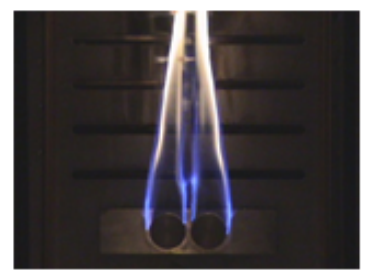

(c)

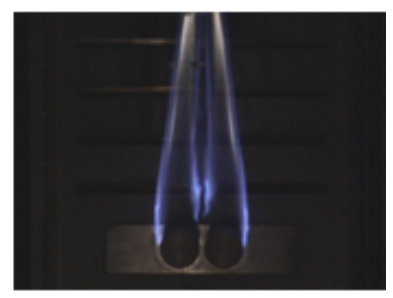

(d)

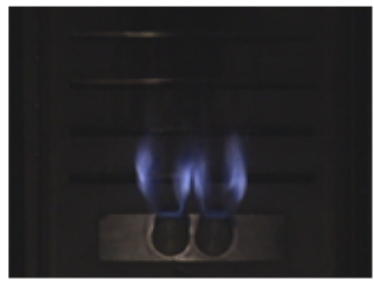

(e)

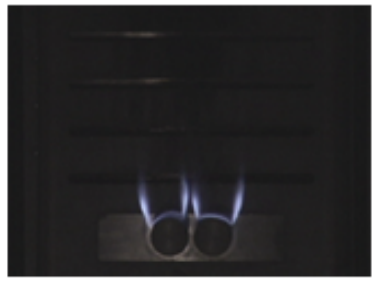

(f)

Fig. 7. Series of flame configurations as a function of inflow velocity $(\mathrm{L}=1.2 \mathrm{D}$, $\mathrm{V}_{\mathrm{w}}=1.23 \mathrm{~cm} / \mathrm{s}$ ), (a) $\mathrm{U}_{\text {in }}=0.48 \mathrm{~m} / \mathrm{s}$ (b) $\mathrm{U}_{\text {in }}=0.83 \mathrm{~m} / \mathrm{s}$ (c) $\mathrm{U}_{\text {in }}=0.87 \mathrm{~m} / \mathrm{s}$ (d) $U_{\text {in }}=0.91 \mathrm{~m} / \mathrm{s}(\mathrm{e}) \mathrm{U}_{\text {in }}=1.85 \mathrm{~m} / \mathrm{s}$ (f) $U_{\text {in }}=3.79 \mathrm{~m} / \mathrm{s}$

As the velocity increases to $0.87 \mathrm{~m} / \mathrm{s}$, the envelope flame front is blown off from the forward stagnation point, forming two wake flames downstream. Because the highvelocity flow can now penetrate the narrow gap, the wake flame fronts in the inner part are slightly downstream of those in the outer part. Now, the point where the two flames merge seems to move further downstream and out of the visible area of the test section. Therefore, two separated flames are observed again. The wake flame front exhibits the character of a premixed flame and, hence, appears blue. Downstream, the luminous yellow zone of each wake flame, displayed in Figure 7, is brighter and wider than that of the inflow velocity at $0.83 \mathrm{~m} / \mathrm{s}$ Figure 7 because more unreacted fuel vapors forward of the burners are carried downstream.

As the inflow velocity increases to $0.91 \mathrm{~m} / \mathrm{s}$, as in Figure 7, the outer flame fronts retreat downstream, and the inner flame fronts are slightly lifted off. Additionally, the appearance of two separate flames is more obvious at this high inflow velocity. The blue zones of the wake flames are larger than at $\mathrm{U}_{\text {in }}=0.87 \mathrm{~m} / \mathrm{s}$ because more air is mixed with the unreacted fuel vapors, broadening the premixed zone. In- 
creasing Uin $=0.91 \mathrm{~m} / \mathrm{s}$ Figure 7 to $U_{\text {in }}=1.85 \mathrm{~m} / \mathrm{s}$ Figure 7 transforms the flame configurations into small blue wake flames with a thin blue flame presented along the rear surface of each burner. Furthermore, the yellow luminous zones completely disappear. The occurrence of the extra flame sheets adjacent to the two burners' rear surfaces may be attributable to the induced flows, which are towards the flame zone in the cross-stream direction because the experiment is three-dimensional. The induced flow can then bring fresh air into the wake region to mix it with the fuel that is injected from the rear surface, forming a flammable mixture. Subsequently, the downstream flame front provides heat to ignite the mixture to form the flame.

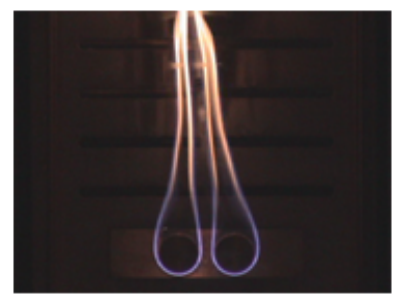

(a)

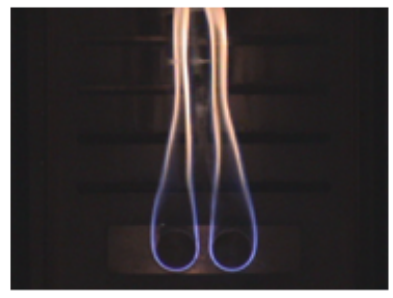

(b)

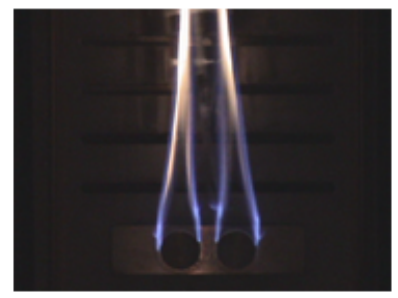

(c)

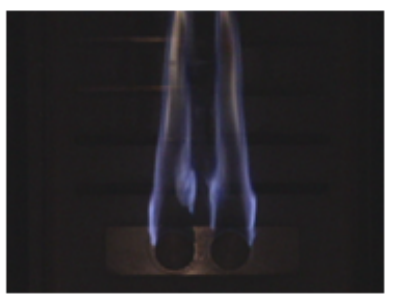

(d)

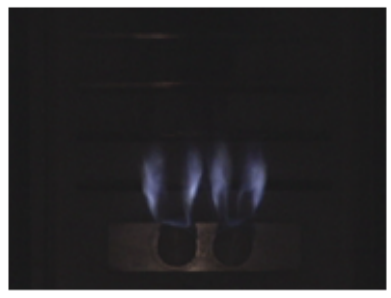

(e)

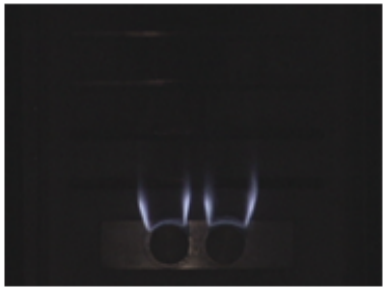

(f)

Fig. 8. Series of flame configurations as a function of inflow velocity $(\mathrm{L}=1.5 \mathrm{D}$, $\mathrm{V}_{\mathrm{w}}=1.23 \mathrm{~cm} / \mathrm{s}$ ), (a) $\mathrm{U}_{\text {in }}=0.48 \mathrm{~m} / \mathrm{s}$ (b) $\mathrm{U}_{\text {in }}=0.65 \mathrm{~m} / \mathrm{s}$ (c) $U_{\text {in }}=0.71 \mathrm{~m} / \mathrm{s}$ (d) $U_{\text {in }}=0.91 \mathrm{~m} / \mathrm{s}$ (e) Uin $=1.85 \mathrm{~m} / \mathrm{s}$ (f) $U_{\text {in }}=3.79 \mathrm{~m} / \mathrm{s}$

Finally, as the inflow velocity increases to $3.79 \mathrm{~m} / \mathrm{s}$, as shown in Figure 7, the wake flame fronts move closer to the rear surfaces of the burners than at $U_{\text {in }}=1.85 \mathrm{~m} / \mathrm{s}$. Hence, the points of attachment move further upstream. However, the wake flames are shortened, whereas the flame sheets on the rear surfaces become broader. For an intercylinder spacing of $1.5 \mathrm{D}$, the transition velocity is $0.71 \mathrm{~m} / \mathrm{s}$, which is less than the $0.87 \mathrm{~m} / \mathrm{s}$ for $L=1.2 \mathrm{D}$ as presented in Figure 6 , because the space between the twin burners is so large that they cannot effectively form a single bluff body. Consequently, the twin burners can only moderately retard the incoming flow intensity. Figure 8 shows the flame configurations for various inflow velocities. In the viewable section, the two envelope flames can be distinguished from each other, as presented in Figure 8. Essentially, the flame configurations at $U_{\text {in }}=0.65 \mathrm{~m} / \mathrm{s}$ are approximately the same as those at $0.48 \mathrm{~m} / \mathrm{s}$. However, for $\mathrm{U}_{\text {in }}=0.48 \mathrm{~m} / \mathrm{s}$, the flame tails merge farther downstream, a phenomenon that does 
not occur when $U_{\text {in }}=0.65 \mathrm{~m} / \mathrm{s}$. Additionally, cold airflow with a high velocity can pass through the gap and move further downstream to separate the two inner flames from each other.

When the inflow velocity is increased to $0.71 \mathrm{~m} / \mathrm{s}$ Figure 8 , the envelope flame fronts disappear in front of the cylinders and form the wake flames. The flame fronts in the inner part of the burners move slightly downstream because of a high velocity resulting from the gap. The yellow regions are brighter than the regions at an inflow velocity of 0.65 $\mathrm{m} / \mathrm{s}$ Figure 8, and the isolation of the two flames are more obvious.

As the inflow velocity increases to $0.91 \mathrm{~m} / \mathrm{s}$ Figure 8, the blue flame zones extend downstream because more air is mixed with the unreacted fuel vapors, broadening the premixed zone. In addition, the flame fronts in the inner part of the dual burners are slightly lifted off, as was observed when $L=1.2 \mathrm{D}$ Figure 8 . When the inflow velocity is 1.85 $\mathrm{m} / \mathrm{s}$ Figure 8, a pair of shortened blue wake flames appears at the back of the burners. A thin blue flame is observed along the rear surface of each burner. Figure 7 shows the mechanism. Increasing the inflow velocity from $1.85 \mathrm{~m} / \mathrm{s}$ Figure 8 to $3.79 \mathrm{~m} / \mathrm{s}$ Figure 8 causes variations of the flame configurations that are similar to those at $L=1.2 \mathrm{D}$. Both wake flames are blue, and a thin blue flame between the two flame fronts appears along the rear surface of each burner. For $L=2 \mathrm{D}$, the transition velocity is $0.68 \mathrm{~m} / \mathrm{s}$, which is slightly less than the velocity for $L=1.5 \mathrm{D}$. The corresponding variation of the flame configuration, displayed in Figure 9, is similar to that in the previous case Figure 8, except that the lift-off of the inner flame fronts occurs as $U_{\text {in }}=1.19$ $\mathrm{m} / \mathrm{s}$ rather than $U_{\text {in }}=0.91 \mathrm{~m} / \mathrm{s}$.

When the intercylinder spacing is equal to or greater than $2.5 \mathrm{D}$, the transition velocities are nearly invariant and equal to $0.65 \mathrm{~m} / \mathrm{s}$. This finding is unsurprising because the flame interference is absent when $L \geqq 2.5 \mathrm{D}$. Notably, the blowing velocity from the cylindrical burners is large in the previous case. Therefore, the two flames are definitely separated when $L \geqq 2.5 \mathrm{D}$. The major difference between Figure $10(L=$ 2.5D) and Figure $9(L=2 \mathrm{D})$ is the absence of lift-off of the inner wake flame front in the present case, verifying that these two flames do not interact with each other and behave separately. As expected, the flame configurations in Figure 11 ( $L$ $=4 \mathrm{D}$ ) should be nearly identical to the corresponding ones in Figure 10 for the same inflow velocity.

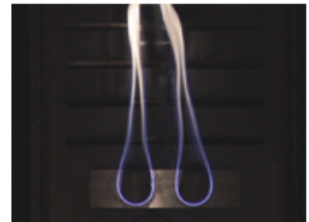

(a)

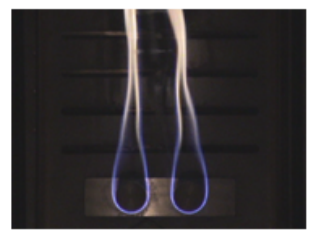

(b)

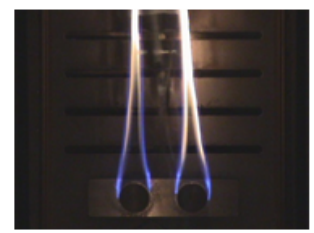

(c)

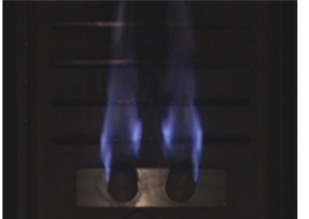

(d)

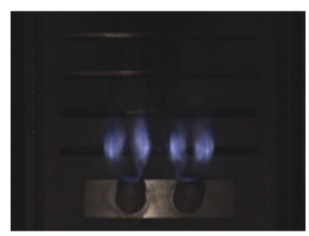

(e)

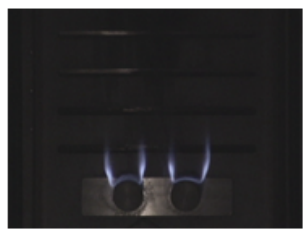

(f)
Fig. 9. Series of flame configurations as a function of inflow velocity $\left(\mathrm{L}=2 \mathrm{D}, \mathrm{V}_{\mathrm{w}}=1.23 \mathrm{~cm} / \mathrm{s}\right.$ ), (a) $\mathrm{U}_{\text {in }}=0.48 \mathrm{~m} / \mathrm{s}$ (b) $U_{\text {in }}=0.65 \mathrm{~m} / \mathrm{s}$ (c) $U_{\text {in }}=0.68 \mathrm{~m} / \mathrm{s}$ (d) $U_{\text {in }}=1.19 \mathrm{~m} / \mathrm{s}$ (e) $U_{\text {in }}=1.85 \mathrm{~m} / \mathrm{s}$ (f) $U_{\text {in }}=3.79 \mathrm{~m} / \mathrm{s}$

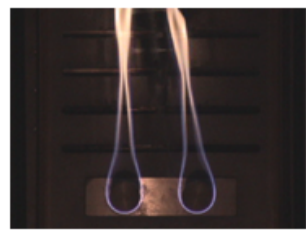

(a)

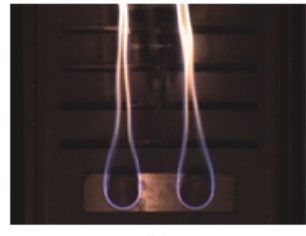

(b)

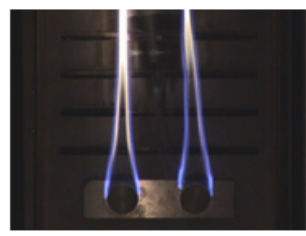

(c)
Fig. 10. Series of flame configurations as a function of inflow velocity $\left(\mathrm{L}=2.5 \mathrm{D}, \mathrm{V}_{\mathrm{w}}=1.23 \mathrm{~cm} / \mathrm{s}\right),(\mathrm{a}) \mathrm{U}_{\mathrm{in}}=0.48 \mathrm{~m} / \mathrm{s}$ (b) $U_{\text {in }}=0.62 \mathrm{~m} / \mathrm{s}$ (c) $U_{\text {in }}=0.65 \mathrm{~m} / \mathrm{s}$ (d) $U_{\text {in }}=1.85$ $\mathrm{m} / \mathrm{s}(\mathrm{e}) \mathrm{U}_{\text {in }}=3.79 \mathrm{~m} / \mathrm{s}$ 


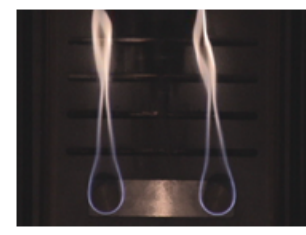

(a)

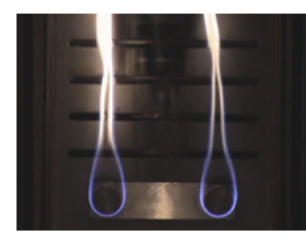

(b)

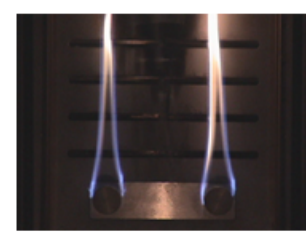

(c)

Fig. 11. Series of flame configurations as a function of inflow velocity ( $\left.\mathrm{L}=4 \mathrm{D}, \mathrm{V}_{\mathrm{w}}=1.23 \mathrm{~cm} / \mathrm{s}\right)$, (a) $\mathrm{U}_{\text {in }}=0.48 \mathrm{~m} / \mathrm{s}$ (b) $U_{\text {in }}=0.62 \mathrm{~m} / \mathrm{s}(\mathrm{c}) \mathrm{U}_{\text {in }}=0.65 \mathrm{~m} / \mathrm{s}$ (d) $U_{\text {in }}=1.85$ $\mathrm{m} / \mathrm{s}(\mathrm{e}) \mathrm{U}_{\text {in }}=3.79 \mathrm{~m} / \mathrm{s}$

\section{B. Comparison with the Simulation of $[7]\left(-f_{w}=0.1\right)$}

Figure 12 plots the transition velocity vs. intercylinder spacing. The non-dimensional fuel ejection rate is fixed at $-\mathrm{f}_{\mathrm{w}}=0.1$. Figure 12 demonstrates that the variation in transition velocity is the same in both studies. Quantitatively, the experimental transition velocity at $L=1.2 \mathrm{D}$ is nearly equal to that predicted by [8]. The discrepancies for $L=$ $1.5 \mathrm{D}$ and $L=2 \mathrm{D}$ are large. The maximum difference is approximately $0.35 \mathrm{~m} / \mathrm{s}$ at $L=2 \mathrm{D}$, which may result from the bistable nature [15]. Finally, the difference decreases and remains at a constant $0.2 \mathrm{~m} / \mathrm{s}$, as $L=2.5 \mathrm{D}$ is increased to $L=$ 4D. The three-dimensionality of the flow in the experiment is believed to be the main cause of these deviations from the two-dimensional prediction.

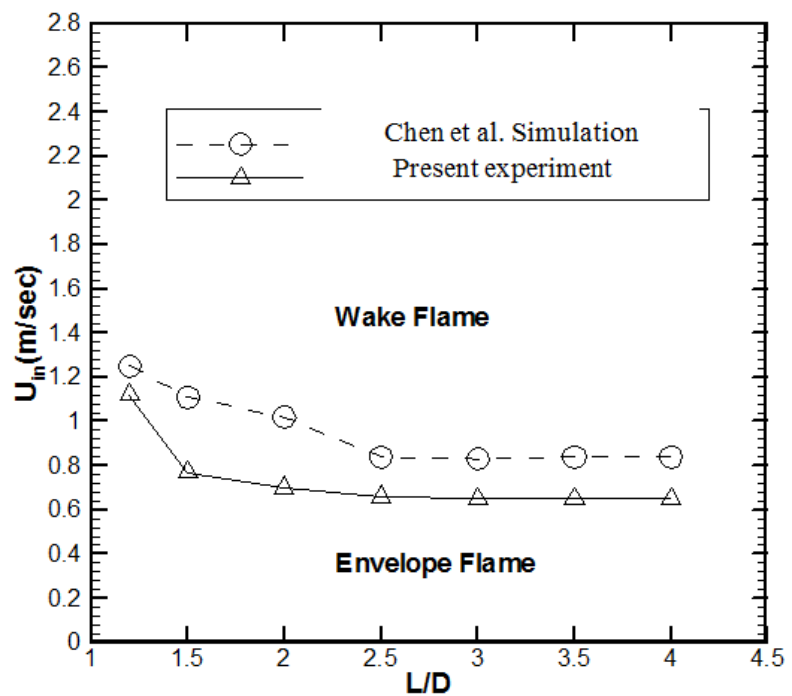

Fig. 12.12 Comparison with the simulation of [7] for the transition velocity as a function of intercylinder spacing $(-\mathrm{fw}=0.1)$

\section{CONCLUDING REMARKS}

This investigation displays the flame transition velocity over dual Tsuji burners for various intercylinder spacing $(L)$. The measurements of the transition velocity as a function of intercylinder spacing at a fixed fuel ejection rate of $1.23 \mathrm{~cm} / \mathrm{s}$ demonstrate that the transition velocity increases as the intercylinder spacing decreases through the range of $1.2 \mathrm{D} \leqq L \leqq 2.5 \mathrm{D}$. When the spacing exceeds $2.5 \mathrm{D}$, the transition velocity remains constant because of an absence of interaction between the flames over the two burners, and no lift-off of the inner wake flame front occurs. Accordingly, when the intercylinder spacing exceeds 2.5D, these flames do not interact with each other and behave as two individual flames.

\section{ACKNOWLEDGMENTS}

The authors would like to thank Academic Research and Solutions Sociedad Limitada for reviewing and correcting this research. Grammatical and writing style errors in the original version have been corrected by Academic Research and Solutions Sociedad Limitada, too.

\section{REFERENCES}

[1] D. Chen, C. Chang, and C. Chen, "Experimental visualizations of counter flow flame behind porous cylinder," Journal of the Chinese Institute of Engineers, vol. 27, no. 3, pp. 321- 330, 2006. doi: https://doi.org/10.1080/02533839.1991. 9677355

[2] H. S. Chai, H. Z. Chen, and C. H. Chen, "Flow past porous cylinder/sphere with/without blowing," Journal of Advances in Technology and Engineering Studies, vol. 4, no. 2, pp. 57-69, 2018. doi: https://doi.org/10.20474/jater-4.2.2

[3] M. Kazuyuki, T. Seiji, M. Takeshi, Y. Minoru, and K. Kenji, "Flame prediction based on harmful expression judgement using distributed representation," International Journal of Technology and Engineering Studies, vol. 4, no. 1, pp. 7-15, 2018. doi: https://doi.org/10.20469/ijtes.4.10002-1 
[4] S.-S. Tsa and C.-H. Chen, "Flame stabilization over a Tsuji burner by four-step chemical reaction," Combustion Science and Technology, vol. 175, no. 11, pp. 2061-2093, 2003. doi: https://doi.org/10.1080/714923186

[5] S. J. Xu, "The effect of interaction between two porous envelope flame and it's extinction mechanism," National Taiwan University, Taipei, Taiwan, Unpublished master's thesis, 1995.

[6] J. Y. Wang, "The effect of interaction between two porous flame mechanism with nitrogen ejector," National Taiwan University, Taipei, Taiwan, Unpublished master's thesis, 1998.

[7] . W. F. B. Chen, C. H., "Flame stabilization and blowoff over a porous cylinder," Combustion Science and Technology, vol. 73, no. 1-3, pp. 427-446, 1990. doi: https://doi.org/10.1080/00102209008951661

[8] D.-D. Chen, S.-S. Tsa, and C.-H. Chen, "Interaction between counterflow flames over binary tsuji burners arranged in side-by-side," Combustion Science and Technology, vol.177, no. 10, pp. 1961-1995, 2005. doi: https://doi.org/10.1080/ 00102200590970348

[9] J. C. Yang, M. K. Donnelly, N. C. Prive, and W. L. Grosshandler, "Dispersed liquid agent fire suppression screen apparatus," National Institute of Standards and Technology, California, CA, Tech. Rep., 1999.

[10] A. Standard, "Laboratory methods of testing fans for rating," American Society of Heating, Refrigerating and AirConditioning Engineers, vol. 2, no. 1, pp. 56 -60, 1985.

[11] S. J. Kline, "Describing uncertainty in single sample experiments," Mechical Engineering, vol. 75, no. 6, pp. 3-8, 1953.

[12] D. F. Young, B. R. Munson, T. H. Okiishi, and W. W. Huebsch, A Brief Introduction to Fluid Mechanics. New York, NY: John Wiley \& Sons, 2010.

[13] R. S. Figliola and D. Beasley, Theory and Design for Mechanical Measurements. New York, NY: John Wiley and Sons, 2015.

[14] J. P. Holman, Experimental Methods for Engineers. New York, NY: McGraw-Hill, 1989.

[15] M. M. Zdravkovich, "Review of flow interference between two circular cylinders in various arrangements," Journal of Fluids Engineering, vol. 28, no. 5, pp. 618-633, 1977. 